\title{
Osteogenic differentiation potential and quantification of fresh and cryopreserved dental follicular stem cells-an in vitro analysis
}

\author{
AlHindi M'1 Philip MR ${ }^{1}$
}

\begin{abstract}
Purpose: To isolate and characterize mesenchymal stem cells of dental follicle from fresh and cryopreserved samples and to test any significant difference in their osteogenic differentiation potential by using digital imaging software. We also investigated whether the cryoprotectant used and its concentration is able to maintain cell count and viability.

Methods: Mesenchymal stem cells (MSCs) were isolated from dental follicle of impacted third molars. The osteogenic differentiation potential of dental follicle stem cells was assessed using alizarin red and alkaline phosphatase staining followed by digital imaging quantification of the stains.
\end{abstract}

Results: Dental follicle cells have shown typical characterisation by exhibiting the stem cell stromal markers and hematopoietic markers, but there was variance in the percentage of expression in fresh and cryopreserved samples. There was considerable osteogenic differentiation potential in the fresh sample compared to cryopreserved sample. The cell count and viability were preserved in both samples.

Conclusions: The results in the study have shown wide variation of osteogenic differentiation potential in fresh and cryopreserved samples. Also, the cryoprotectant was found to be effective in its purpose at the specified concentration.

Key Words: Dental follicle; Mesenchymal stem cells; Cryopreservant; Osteogenic differentiation; Digital imaging

\section{Introduction}

Mesenchymal stem cells (MSCs) have proved to be invaluable in regenerative medicine because of their two remarkable characteristics of self-renewal and multi-lineage differentiation. Stem cells can broadly be classified as Embryonic Stem Cells (ESCs) and Adult Stem Cells (ASCs), based on their origin and differentiation potential ${ }^{[1,2,3]}$. The ASCs isolated from various dental tissues are commonly referred to as Dental Stem Cells (DSCs). MSCs were first isolated by Gronthos et al. from dental pulp (DPSCs) ${ }^{[4]}$ and subsequently from the dental pulp of human exfoliated deciduous teeth (SHEDs) ${ }^{[5]}$. The dental follicle is a loose connective tissue that surrounds the developing tooth and is separated from dentin by an epithelial layer (Hertwig's sheath) with three distinct stem cell populations (hDF1, hDF2, hDF3), distinct morphologies, gene expression and differentiation potential ${ }^{[6,7]}$. Dental follicle stem cells (DFSCs) are known as the progenitor cells for the formation of all periodontium related tissues, including periodontal ligament, cementum and alveolar bone ${ }^{[8]}$. DFSCs can be isolated from developing tissues, compared to other stem cells of dental tissue origin ${ }^{[9]}$. DFSCs also express surface antigen markers similar to the other dental stem cells (positive for CD44, CD105, CD29, negative for CD34, CD117, the putative stem cell markers Notch-1 and Nestin) ${ }^{[10]}$. DFSCs are obtained easily after tooth extraction. DFSCs are also available from inflamed or diseased dental tissues and exhibit properties similar to those of DFSCs obtained from healthy tissues $^{[11]}$. Interestingly, the DFSCs manifest characteristics of both mesoderm and ectoderm, which contributes to the union of mesenchymal stem cells (required for the formation of odontoblasts, cementoblasts, osteoblasts, fibroblasts) and epithelial stem cells (involved in forming ameloblasts), which is imperative for regenerating a new tooth ${ }^{[2,12]}$. DFSCs exhibit fibroblastic morphology and excellent proliferative capacity, with selective adherence to solid surfaces. They can be cryopreserved for either research or future medical therapy. Cryopreservation is done to prevent contamination by microorganisms and other cell lines and used for long term maintenance. Freezing media is a serum-free media with dimethyl sulphoxide (DMSO) in $10 \%$ concentration as cryoprotectant. There is controversy regarding the optimal cryoprotective agent and the concentration required to minimise cytotoxicity of the banked cells, the minimum number of cells required for cryopreservation to obtain viable cell lines after thawing, the storage time and the storage temperature.

The objectives of our research were to isolate and characterise mesenchymal stem cells from the dental follicle of fresh and cryopreserved samples harvested from third molar sites and to test any significant difference in their in vitro osteogenic differentiation potential by quantifying the expression of alkaline phosphatase and alizarin red stains using digital imaging software. We have come across many methods for cryopreservation of dental stem cells to maintain their pluripotency after cryopreservation. But literature is still lacking related to the concentration and method of cryopreservation adequate to maintain cell viability and count without causing cytotoxicity. Here, we assessed the efficacy of the 
cryopreservant in a predetermined concentration in maintaining cell count and viability, as well as the scope for preserving fresh samples for osteogenic differentiation compared to cryopreserved ones.

\section{Methods}

\section{DFSC culturing and cryopreservation}

Discarded dental follicles from extracted third molar sites from patients in the age range of 14 to 28 years who underwent removal of immature impacted third molars for orthodontic reasons were taken for the isolation and culture of DFSCs. Nine samples were obtained from healthy subjects and processed on the same day. No associated pathology was noted in any of these samples. Tooth germs were removed under approved guidelines and dental follicle separated and placed in Dulbeccos phosphate buffered saline (D-PBS). Under aseptic conditions, the tissues were minced into $1-3 \mathrm{~mm}$ explants, transferred to sterile bottles, washed with PBS. To this, $1 \mathrm{ml}$ collagenase $3 \mathrm{mg} / \mathrm{ml}$ was added for tissue digestion and placed in agitation in a shaker incubator at $37^{\circ} \mathrm{C}$ for $40 \mathrm{~min}$ to separate cells. When taken out after 40 min, cells were resuspended using pipettes, and the solution was checked for cells. If found positive for cells, the solution was centrifuged at $1500 \mathrm{rpm}$ for $5 \mathrm{~min}$ to get the cell pellet. After adding 4 $\mathrm{ml}$ DMEM to the test tube, the cells were resuspended and the solution pipetted into $25 \mathrm{~cm}^{2}$ tissue culture vented flasks and placed in an incubator in a humidified atmosphere at $37^{\circ} \mathrm{C}$ with $5 \% \mathrm{CO}_{2}$ for the culture of DFSC. DFSCs were cultured in alpha minimum essential medium (GIBCO); total media was 500ml, DMEM-440 ml, 10\% FBS$50 \mathrm{ml}$, Pen-strep-5ml, NEAA-5ml. Following trypsinisation, cells were counted, centrifuged with PBS, the supernatant removed, $4 \mathrm{ml}$ DMEM was added and the mixture subcultured similarly in $75 \mathrm{~cm}^{2}$ tissue culture flasks for 2 to 3 passages, with six samples being cryopreserved for later use. For cryopreservation, the cells were resuspended in $1 \mathrm{ml}$ freezing media and aliquoted to two cryogenic storage vials. Freezing was carried out using the gradual cooling method, initially at temperatures of $-80^{\circ} \mathrm{C}$ in a freezer and later moving the mixture into a liquid nitrogen tank with liquid nitrogen in two phases, a liquid phase at $-196^{\circ} \mathrm{C}$ and vapour phase at $-156^{\circ} \mathrm{C}$. For this, $50 \mathrm{ml}$ freezing media was prepared in the following composition: $10 \mathrm{ml}$ of $20 \% \mathrm{FBS}, 1 \%$ of $0.5 \mathrm{ml}$ Penicillin-streptomycin, $5 \mathrm{ml}$ of $10 \%$ DMSO and $34.5 \mathrm{ml}$ DMEM.

\section{Morphologic characterisation of cells}

The samples were taken from cryo-storage for morphologic characterisation at different time periods by thawing the vial in a water bath at $37^{\circ} \mathrm{C}$ and adding cells dropwise into a labelled tube containing $1 \mathrm{ml}$ medium (DMEM). The tube was centrifuged, cells were suspended in $4 \mathrm{ml}$ DMEM and cultured in $25 \mathrm{~cm}^{2}$ flasks. DFSCs were examined under a light microscope when the cell proliferation showed $80 \%$ confluency and cell proliferation rate was assessed by taking cell count at this point.

\section{Characterisation of MSCs by flow cytometry}

From each frozen sample, after thawing, one vial was cultured for characterisation by flow cytometry and a second vial for osteo differentiation. The cells were characterised using flow cytometry. Fluorescein isothiocyanate (FITC), conjugated or phycoerythrin (PE)conjugated $\mathrm{mAbs}$ and $\mathrm{APC}$ stains were used for immune phenotypical analysis of DFSCs. CD73PE, CD29PE, CD90FITC, CD105PE, CD 44 APC were used as stromal cell-associated markers, CD-31FITC, CD14APC, CD-34FITC, CD-45 FITC as hematopoietic/endothelial cell markers, HLADRPE as Class $11 \mathrm{MHC}$ and Iso FITC, Iso PE, Iso APC were used as isotype controls.

\section{Osteogenic differentiation potential of DFSCs}

Two samples were selected for osteogenic differentiation for 15 days, one fresh and one cryopreserved. Cells were grown in a commercial osteogenic induction medium (MesenCult ${ }^{\mathrm{TM}}$ osteogenic differentiation kit, Catalog\#05465) for 15 days, to assess the ability of DFSC to form mineralised nodules in vitro. Expression of alkaline phosphatase stain, a typical osteoblast marker, was assessed in DFSCs, along with alizarin red stain. Alizarin red $\mathrm{S}$ staining was done to isolate extracellular calcium deposits of cells differentiated into osteoblasts. After culturing for 15 days, we fixed the cells for a maximum of $5 \mathrm{~min}$ with ethylene hydroxide (EtOH). Alizarin red $(40 \mathrm{mM}, \mathrm{pH} 4.1$, Catalogue\#0223) was used for staining. The cells were examined under a bright-field microscope, when deposits of calcium exhibited a bright orange-red colour. Photographs were taken in $5 \mathrm{X}$ and $10 \mathrm{X}$ magnification of each well, and the images analysed quantitatively by using Image $J$ software according to the standardised protocol. Software setup was done initially by going to menu-analyse-set scale $<$ distance in pixels $=637.6$, known distance 1 , unit of length in $\mathrm{mm}<\mathrm{OK}<$ type of image $<\mathrm{RGB}<$ split image $<$ select green channel $<$ image-adjust threshold, and colour thresholding used. The pixels in the threshold range are displayed in red. All samples were evaluated using the same threshold -select analyse $<$ measurement $<$ select area, fraction, limit to threshold, display label $<\mathrm{OK}<$ analyse $<$ measure. We used area percentage as our read out and calculated the fold change in the staining area.

\section{Results}

Rate of cell growth and morphology

Cultures were found positive for cells in $25 \mathrm{ml}$ tissue culture flasks (TCF) under an inverted microscope. Cells were noticed positive at 5 to 7 days in all samples, showing spindle-shaped fibroblastic morphology. Two samples were discarded due to contamination. Six samples underwent 2 passages before cryopreservation, and the last subculture was done in $75 \mathrm{ml}$ TCF. One sample which did not undergo cryopreservation became positive for stem cells in 7 days and underwent 3 passages and survived long term culture for 44 days before being taken for characterisation and osteogenic differentiation. Cell growth was calculated by taking the cell count before freezing the samples for an average of 21 days, and the average cell count was $1.607 \times 10^{6} \mathrm{cells} / \mathrm{ml}$. Samples were cryopreserved for a period ranging from 3 months to one year before being taken for characterisation. Although cells were positive and viable in cryopreserved samples, cell count had decreased to an average of $0.58 \times 10^{6}$ cells $/ \mathrm{ml}$, as they were stored in 2 separate vials while being frozen, so they were subjected to subculture before undertaking characterisation and differentiation.

\section{Characterisation of MSC markers in fresh and cryopreserved samples}

All hematopoietic stem cell markers were found to be negative or weakly positive, and HLA-DR was found to be negative in all samples, regardless of whether they were cryopreserved or fresh. CD 34 and CD 14 showed variable expression of sometimes positive and sometimes negative, as they also represent primitive stromal cells other than hematopoietic cells. Fresh sample without cryopreservation showed 95\% fluorescence for all stromal cell-associated MSC markers, whereas cryopreserved samples showed an average immunofluorescence of $92.3 \%$ for CD44APC, $90.6 \%$ for CD73PE, $85.6 \%$ for CD 29PE, $97 \%$ for CD13APC, $90.5 \%$ for CD 90 FITC, $15 \%$ for CD146PE and $43.2 \%$ for CD 105PE. MSC phenotypic analysis by FACS is shown in Figure 1 and Table 1. 
Hematopoietic Lineage Markers
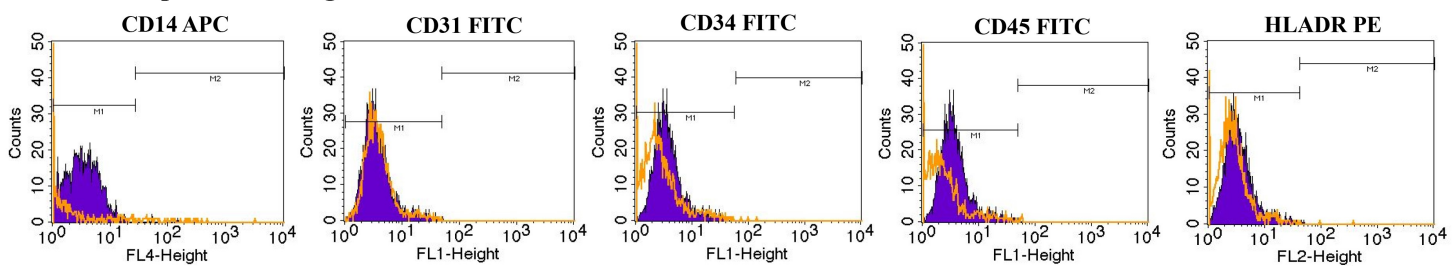

Stromal Cell Associated Markers
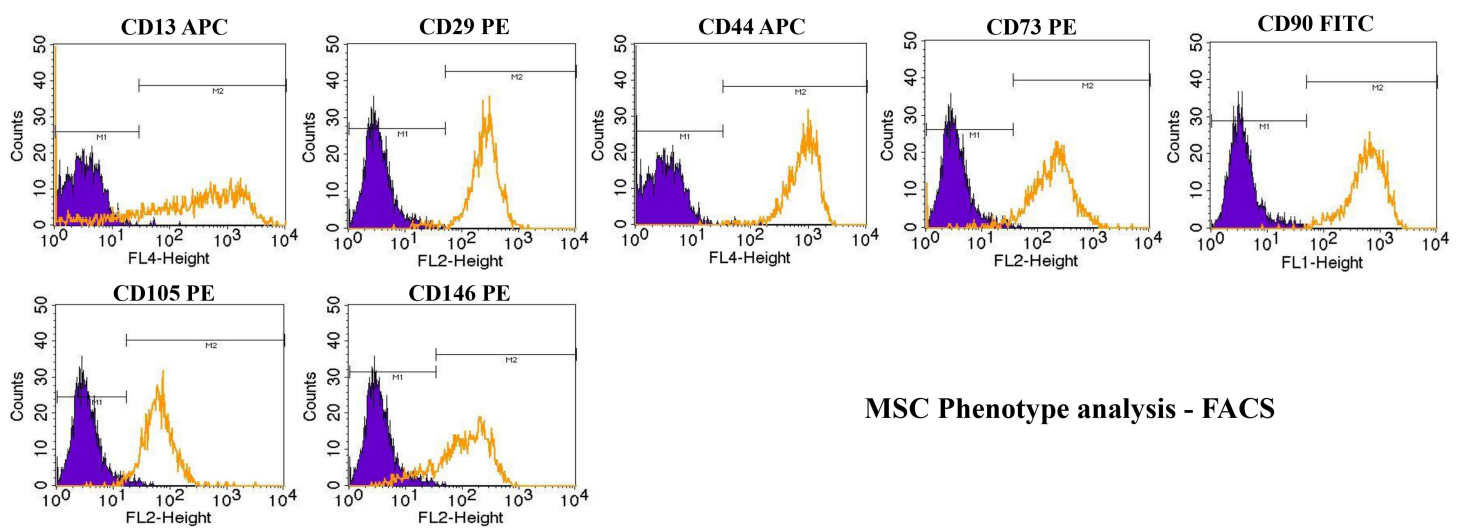

\section{MSC Phenotype analysis - FACS}

Figure 1: MSC Phenotypical analysis

Sample : 220486dp

Day 15 Control
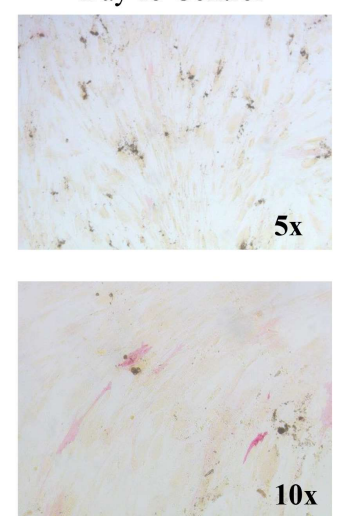

ALP stain

\section{MSC Osteo Differentiation}

Day 15 Test
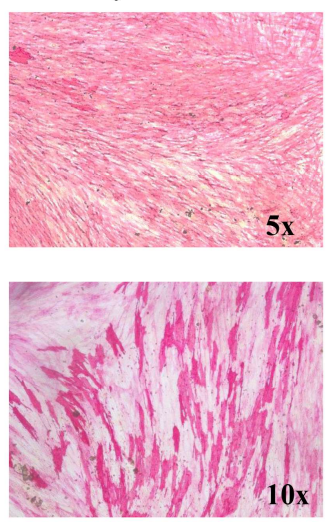

Day 15 Control
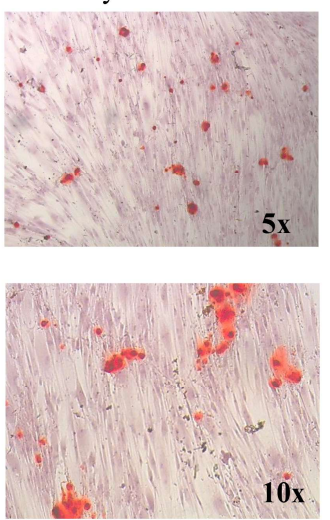

Alizarin Red stain
Day 15 Test
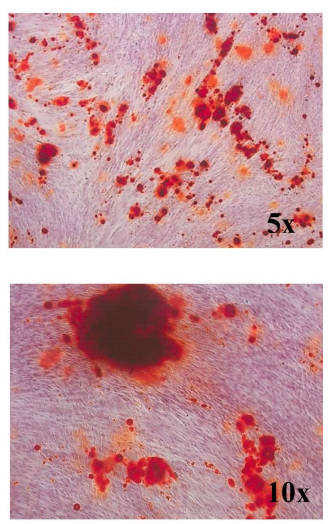

Figure 2: MSC osteodifferentiation of fresh sample

Table 1: Distribution of MSC and Hematopoetic marker expression

\begin{tabular}{ccccccccccccc}
\hline $\begin{array}{c}\text { CD } \\
\text { Markers \% }\end{array}$ & $\begin{array}{c}\text { CD45 } \\
\text { FITC }\end{array}$ & $\begin{array}{c}\text { CD34 } \\
\text { FITC }\end{array}$ & $\begin{array}{c}\text { CD31 } \\
\text { FITC }\end{array}$ & $\begin{array}{c}\text { CD14 } \\
\text { APC }\end{array}$ & $\begin{array}{c}\text { HLADR } \\
\text { PE }\end{array}$ & $\begin{array}{c}\text { CD73 } \\
\text { PE }\end{array}$ & $\begin{array}{c}\text { CD29 } \\
\text { PE }\end{array}$ & $\begin{array}{c}\text { CD44 } \\
\text { APC }\end{array}$ & $\begin{array}{c}\text { CD13 } \\
\text { APC }\end{array}$ & $\begin{array}{c}\text { CD90 } \\
\text { FITC }\end{array}$ & $\begin{array}{c}\text { CD105 } \\
\text { PE }\end{array}$ & $\begin{array}{c}\text { CD146 } \\
\text { PE }\end{array}$ \\
\hline $\begin{array}{c}\text { Sample } \\
\text { name }\end{array}$ & & & & & & & & & & & & \\
\hline 22 MPMF & 0 & 5 & 0 & 5 & 0 & 76 & 62 & 85 & 95 & 76 & 21 & 30 \\
\hline 220486 & 0 & 2 & 0 & 2 & 0 & 98 & 99 & 99 & 85 & 99 & 90 & 90 \\
\hline $2134 M P M F$ & 0 & 0 & 0 & 0 & 3 & 99 & 99 & 99 & 99 & 99 & 90 & 0 \\
\hline DFSCP2 & ND & ND & 0 & 2 & 0 & 98 & 99 & ND & ND & ND & 35 & ND \\
\hline DF22212 & ND & ND & ND & ND & ND & 85 & 70 & ND & ND & 95 & 0 & ND \\
\hline DF311dp & 0 & ND & 0 & 14 & 0 & 95 & 98 & 93 & ND & 92 & 70 & ND \\
\hline ND-not determined & & & & & & & & & & & & P30
\end{tabular}


Sample :

311dp
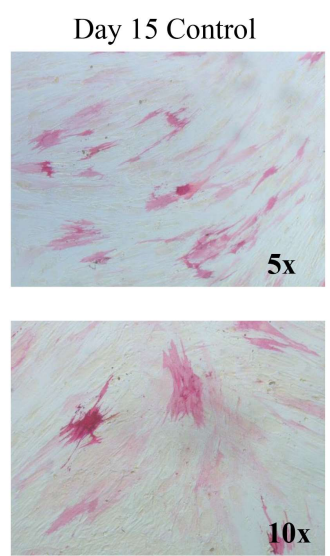

10x
MSC Osteo Differentiation
Day 15 Test
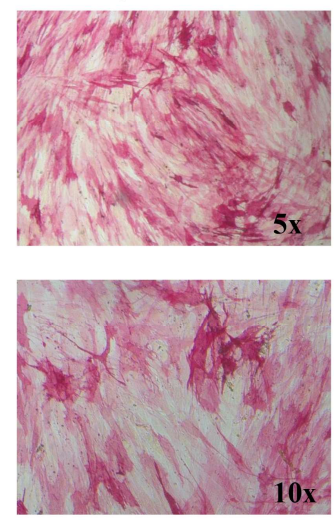

ALP stain
Day 15 Control
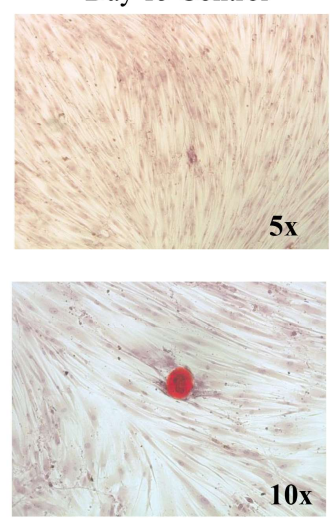

Day 15 Test
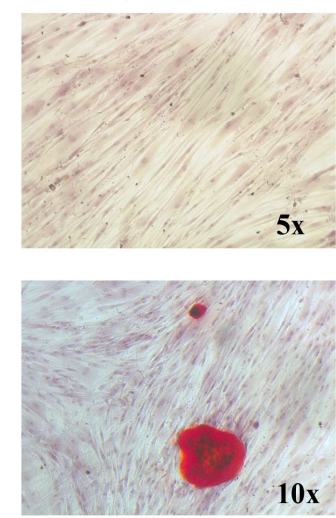

$10 \mathrm{x}$

Alizarin Red stain

Figure 3: MSC osteodifferentiation of cryopreserved sample

Table 2. Fold change distribution of fresh and cryopreserved samples for the ALP and AzR stains showing osteogenic differentiation potential.

\begin{tabular}{cccccccc}
\hline \multirow{2}{*}{ Samples } & \multicolumn{3}{c}{ Test \% } & \multicolumn{2}{c}{ Control \% } & Fold change \\
\cline { 2 - 7 } & ALP & Az R & ALP & Az r & ALP & Az R \\
\hline $\begin{array}{c}\text { Cryopreserved } \\
311 \mathrm{dp}\end{array}$ & 6.607 & 4.416 & 0.460 & 0.678 & 13.363 & 5.513 \\
\hline $\begin{array}{c}\text { Fresh } \\
220486 \mathrm{dp}\end{array}$ & 4.391 & 18.369 & 0.021 & 0.414 & 208.09 & 43.369 \\
\hline \multicolumn{7}{c}{ ALP-alkaline phosphatase, AzR -Alizarin red } \\
\hline
\end{tabular}

\section{Osteogenic differentiation of fresh and cryopreserved samples}

\section{Alizarin red staining and digital imaging quantification of stains}

Two samples were selected for osteogenic differentiation for 15 days, one fresh and one cryopreserved. Staining with alizarin red $\mathrm{S}$ allows a demonstration of extracellular calcium deposits in a bright orange-red colour. Staining revealed that although DFPCs cultured in a control medium (CM) were able to form mineralised nodules, they were markedly less than from DFPCs cultured in test samples in osteogenic medium (Figures 2 and 3). As alizarin red staining is somewhat nonspecific, quantification of the calcium content of the deposited matrix was also done by digitally quantifying the stain image at a fixed threshold in both samples. In the cryopreserved sample, the fold change observed for alizarin red stain was 5.513, while in the fresh sample the change was 43.369 (Table 2).

\section{Alkaline phosphatase ALP staining and digital imaging quantification of stains}

When cultured for 15 days in an osteogenic medium, DFPCs showed a dense mineralised plexus in test samples (Figures 2 and 3).
ALP or alkaline phosphatase, a widely expressed hydrolase enzyme in hard tissue mineralisation, provides free phosphate that is required for the creation of hydroxyapatite crystals ${ }^{[18]}$. Alkaline phosphatase stained test and control sample images were also digitally scanned for quantification. In the cryopreserved sample, the fold change observed for alkaline phosphatase was 13.363 and in the fresh sample, it was 208.09 (Table 2). Values differ widely for both stains in fresh and cryopreserved samples.

\section{Discussion}

Comparison of fresh and cryopreserved samples

Recent literature has reported limited but significant differences in the expression of physiological properties between fresh and thawed samples. However, prospective randomised clinical studies to assess their therapeutic value are still lacking. The possibly compromised immunomodulatory activity directly after thawing may be a reason for failure in clinical trials, as the recovery time for MSCs from the cryo-stun effect is still unknown ${ }^{[13]}$. A few studies have revealed altered physiological properties such as membrane asymmetry which lead to cell injury and disintegration, while some studies reported no differences between fresh and 
thawed samples ${ }^{[14,15]}$. Conflicting results are also seen related to cell growth, differentiation, general phenotype, viability and bio activity of fresh and thawed samples ${ }^{[15,16,17]}$. Our research mainly emphasised finding out any differences observed in the osteogenic differentiation potential of fresh and cryopreserved samples. Figures 2 and 3 and Table 1 clearly show that cryopreservation negatively affects the osteogenic differentiation potential of dental follicles. We also observed a variable expression of MSC phenotypical markers between the two samples. (Table 2)

Factors affecting the osteogenic differentiation of dental follicular stem cells

Although ex vivo expanded mouse or bovine DFSCs transplanted into immunosuppressed mice are capable of forming cementum- or PDL-like structures ${ }^{[18]}$, studies on the ability of DFSCs to form hard tissues are still not sufficient. The subcutaneous transplantation of DFSCs was reported to have no effect on the formation of any type of hard tissue in immunocompromised mice ${ }^{[8]}$. Osteogenic differentiation is a multifactorial process employing soluble inducing factors along with extracellular supporting conditions ${ }^{[19]}$. That osteocytes are more influential than osteoblasts in stimulating osteogenesis was established when MSCs co-cultured with osteocytes showed increased calcium content ${ }^{[20]}$. An increase in ALP activity is known to accompany osteogenic differentiation. The wellestablished osteogenic markers include Runt Related Transcription Factor 2 (RUNX2), osterix (SP7/OSX) and alkaline phosphatase $(A L P)$. DFPCs have shown in vitro the potential to undergo osteogenic, adipogenic, chondrogenic and neurogenic differentiation in both mice and rats ${ }^{[21]}$. DFSCs produced bone in vitro in collagen scaffold 3D cultures, as shown by mRNA expression of bone markers such as ALP and alizarin red. For bone regeneration scaffolds, a pore size in the range of $150-400 \mu \mathrm{m}$ is required to promote bone formation and vascularisation ${ }^{[22]}$. There are many extrinsic and intrinsic time-dependent factors that influence MSC production and their therapeutic properties, such as donor age and time in culture ${ }^{[13]}$. DFPCs' limitation is that they are only available from patients during wisdom tooth eruption, usually between 15 and 28 years of age ${ }^{[23]}$. There will be a gradual loss of progenitor properties and tissue forming capacity after expansion and repeated passaging ${ }^{[24,25,26,27]}$. Consequently, here we emphasised assessing the functional potency after cryobanking. Similar to the findings in other studies $^{[23,28]}$, DFPCs employed here expressed CD9, CD10, CD13, CD29, CD44, CD53, CD59, CD73, CD90, CD105, CD106 and CD166 surface markers and were negative for the hematopoietic antigens CD34 and CD45, CD117 and HLA-DR. This study has demonstrated expression of more than 95\% fluorescence for all stromal cell- associated MSC markers in a fresh sample, whereas fluorescence expression in five cryopreserved samples was variable and decreased.

\section{Digital imaging quantification of stains}

An intensive review of in vitro and in vivo studies is essential to assess the efficacy of dental MSCs in bone regeneration ${ }^{[29]}$. This study used quantification of the expression of ALP and alizarin red stains employing image analysis software, which is non-destructive. It makes quantification faster, more objective and less laborious than visual examination.

\section{Efficacy of cryopreservant in 10\% concentration}

We assessed the efficacy of the cryopreservant in $10 \%$ concentration as well as the scope of preserving fresh samples for osteogenic differentiation compared to cryopreserved ones. The easy accessibility to dental MSCs makes them an excellent alternative to BMMSCs for use in clinical trials ${ }^{[30]}$. However, the cryopreservation procedure employed must follow standardised protocols to safeguard the biological product, as they are intended for clinical use. Factors like type, concentration, dilution of the cryoprotective agent (CPA), the freezing rate and thawing conditions should be taken into account. DMSO as a CPA used in research is a cytotoxic chemical that has been reported to cause epigenetic changes and cytotoxicity at levels routinely used for MSC cryopreservation ${ }^{[31]}$. A review of the literature showed that $80 \%$ of stem cell banks most commonly employ $10 \% \mathrm{DMSO}^{[32]}$. The survival and number of colonies formed by MSCs were significantly decreased by reducing the concentration of DMSO, and the magnitude of this decrease was inversely proportional to DMSO concentration ${ }^{[33]}$. The recommendation to cryopreserve stem cell populations of at least 1 million cells ${ }^{[2]}$ in order to compensate is followed in this study. Controlling the freezing rate is essential to minimise the damage caused by cell dehydration and ice crystal formation. A slow and controlled freezing rate of $1-2^{\circ} \mathrm{C}$ per minute is generally considered optimal for maintaining MSC viability during cryopreservation ${ }^{[34]}$. The ability of DFSCs to maintain their characteristics for years after cryopreservation is critical if they are intended for clinical use. Although, there was a difference noticed in the average cell count before and after cryopreservation, which can be attributed to the separation of cells into two vials before cryopreservation, this study did not find any significant change in viability or cell count in cryopreserved samples. The average cell count was $1.607 \mathrm{X} 10^{6}$ cells $/ \mathrm{ml}$ before cryopreservation and $0.58 \times 10^{6}$ cells $/ \mathrm{ml}$ after cryopreservation in each vial. The major drawbacks of the study were the limited number of fresh samples employed to check differentiation potential. Moreover, we were unable to check the recovery time for thawed samples for optimal osteogenic differentiation, and also could not test for pre osteoblast markers like $R U N X 2$ or osterix. However, we were successful in gaining insight into using fresh samples whenever possible for better osteogenic results, emphasising that preservation of fresh samples is a technique-sensitive procedure.

\section{Conclusions}

A fresh sample could ensure long term survival during cultures, undergoing multiple cell passaging with good proliferation rates, and retained more than $95 \%$ fluorescence in the expression of all mesenchymal stem cell markers. It also exhibited marked osteogenic differentiation potential compared to the cryopreserved one. Further, this study proves that DFSCs can be cryopreserved and stored for long periods without losing cell count and viability, by using a cryoprotectant in the specified concentration.

\section{References}

1. Tatullo M, Marrelli M, Paduano F. The regenerative medicine in oral and maxillofacial surgery: the most important innovations in the clinical application of mesenchymal stem cells. Int J Med Sci. 2015;12(1):72-7.

2. Barbara Z, Eriberto B, editors. Dental stem cells: Regenerative potential (Stem cell biology and Regenerative medicine). 1st ed.Springer.com: Humana press;2016.

3. Potdar PD, Jethmalani YD. Human dental pulp stem cells: applications in future regenerative medicine. World J Stem Cells. 2015;7(5):839-51.

4. Laino G, d'Aquino R, Graziano A, Lanza V, Carinci F, Naro F, Pirozzi G, Papaccio G. A new population of human adult dental pulp stem cells: a useful source of living autologous fibrous bone tissue (LAB). J Bone Miner Res. 2005;20(8):1394-402. 
5. Patil R, Kumar BM, Lee WJ, Jeon RH, Jang SJ, Lee YM, Park BW, Byun JH, Ahn CS, Kim JW, Rho GJ. Multilineage potential and proteomic profiling of human dental stem cells derived from a single donor. Exp Cell Res. 2014;320(1):92-107.

6. Morsczeck C, Götz W, Schierholz J, Zeilhofer F, Kühn U, Möhl C, Sippel C, Hoffmann KH. Isolation of precursor cells (PCs) from human dental follicle of wisdom teeth. Matrix Biol. 2005;24(2):155-65.

7. Vishwakarma A, Sharpe P, Shi S, Ramalingam M, editors. Stem cell biology and tissue engineering in dental sciences. 1st ed. London: Academic Press;2014.

8. Morsczeck C, Moehl C, Götz W, Heredia A, Schäffer TE, Eckstein N, Sippel C, Hoffmann KH. In vitro differentiation of human dental follicle cells with dexamethasone and insulin. Cell Biol Int 2005;29(7):567-75.

9. Estrela C, Alencar AH, Kitten GT, Vencio EF, Gava E. Mesenchymal stem cells in the dental tissues: perspectives for tissue regeneration. Braz Dent J. 2011;22(2):91-8.

10. Vollkommer T, Gosau M, Felthaus O, Reichert TE, Morsczeck C, Götz W. Genome-wide gene expression profiles of dental follicle stem cells. Acta Odontol Scand. 2015;73(2):93-100.

11. Alongi DJ, Yamaza T, Song Y,Fouad AF, Romberg EE, Shi S, Tuan RS, Huang GT. Stem/progenitor cells from inflamed human dental pulp retain tissue regeneration potential. Regen Med. 2010; 5(4):617-31.

12. Huang GT, Gronthos S, Shi S. Mesenchymal stem cells derived from dental tissues vs.those from other sources: their biology and role in regenerative medicine. J Dent Res. 2009;88(9):792-806.

13. Moll G, Geißler S, Catar R, Ignatowicz L, Hoogduijn MJ, Strunk D, Bieback K, Ringdén O. Cryopreserved or Fresh Mesenchymal Stromal Cells: Only a Matter of Taste or Key to Unleash the Full Clinical Potential of MSC Therapy? Adv Exp Med Biol. 2016;951:77-98

14. Moll G, Alm JJ, Davies LC, von Bahr L, Heldring N, StenbeckFunke L, Hamad OA, Hinsch R, Ignatowicz L, Locke M, Lönnies H, Lambris JD, Teramura Y, Nilsson-Ekdahl K, Nilsson B, Le Blanc K. Do cryopreserved mesenchymal stromal cells display impaired immunomodulatory and therapeutic properties? Stem Cells. 2014;32(9):2430-42.

15. Yong KW, Pingguan-Murphy B, Xu F, Abas WA, Choi JR, Omar SZ, Azmi MA, Chua KH, Wan Safwani WK. Phenotypic and functional characterization of long-term cryopreserved human adipose-derived stem cells. Sci Rep. 2015;5:9596.

16. Mamidi MK, Nathan KG, Singh G, Thrichelvam ST, Mohd Yusof NA, Fakharuzi NA, Zakaria Z, Bhonde R, Das AK, Majumdar AS. Comparative cellular and molecular analyses of pooled bone marrow multipotent mesenchymal stromal cells during continuous passaging and after successive cryopreservation. J Cell Biochem. 2012;113(10):3153-64.

17. Hoogduijn MJ, de Witte SF, Luk F, van den Hout-van Vroonhoven MC, Ignatowicz L, Catar R, Strini T, Korevaar SS, van IJcken WF, Betjes MG, Franquesa M, Moll G, Baan CC. Effects of FreezeThawing and Intravenous Infusion on Mesenchymal Stromal Cell Gene Expression. Stem Cells Dev. 2016;25(8):586-97.

18. Handa K, Saito M, Tsunoda A, Yamauchi M, Hattori S, Sato S, Toyoda M, Teranaka T, Narayanan AS. Progenitor cells from dental follicle are able to form cementum matrix in vivo. Connect Tissue Res. 2002;43(2-3):406-8.
19. Y Han, X Li, Y Zhang, Y Han, F Chang, J Ding. Mesenchymal Stem Cells for Regenerative Medicine. Cells. 2019; 8(8): 886.

20. Birmingham E, Niebur GL, McHugh PE, Shaw G, Barry FP, McNamara LM. Osteogenic differentiation of mesenchymal stem cells is regulated by osteocyte and osteoblast cells in a simplified bone niche. Eur Cell Mater. 2012;23:13-27

21. Luan $\mathrm{X}$, Ito $\mathrm{Y}$, Dangaria S,Diekwisch TG.Dental follicle progenitor cell heterogeneity in the developing mouse periodontium. Stem Cells Dev. 2006; 15(4):595-608.

22. Persson M, Lehenkari PP, Berglin L, Turunen S, Finnilä MAJ, Risteli J, Skrifvars M, Tuukkanen J. Osteogenic Differentiation of Human Mesenchymal Stem cells in a 3D Woven Scaffold. Sci Rep. 2018;8(1):10457.

23. Morsczeck C, Schmalz G, Reichert TE,Vollner F, Galler K,Driemel O.Somatic stem cells for regenerative dentistry. Clin Oral Investig. 2008;12(2):113-8.

24. Wagner B, Henschler R. Fate of intravenously injected mesenchymal stem cells and significance for clinical application. Adv Biochem Eng Biotechnol. 2013;130:19-37.

25. Wagner W, Bork S, Lepperdinger G, Joussen S, Ma N, Strunk D, Koch C. How to track cellular aging of mesenchymal stromal cells? Aging (Albany NY). 2010;2(4):224-30

26. Pal R, Hanwate M, Totey SM. Effect of holding time, temperature and different parenteral solutions on viability and functionality of adult bone marrow-derived mesenchymal stem cells before transplantation. J Tissue Eng Regen Med. 2008;2(7):436-44.

27. Otsuru S, Hofmann TJ, Raman P, Olson TS, Guess AJ, Dominici M, Horwitz EM. Genomic and functional comparison of mesenchymal stromal cells prepared using two isolation methods. Cytotherapy. 2015;17(3):262-70.

28. Morsczeck C, Völlner F, Saugspier M, Brandl C, Reichert TE, Driemel O, Schmalz G.Comparison of human dental follicle cells (DFCs) and stem cells from human exfoliated deciduous teeth (SHED after neural differentiation in vitro. Clin Oral Investig. 2010;14(4):433-40.

29. Morad G,Kheiri L, Khojasteh A. Dental pulp stem cells for in vivo bone regeneration: a systematic review of literature. Archives of Oral Biology. 2013; 58 (12), 1818-27.

30. Ramamoorthi M, Bakkar M, Jordan J, Tran SD. Osteogenic Potential of Dental Mesenchymal Stem Cells in Preclinical Studies: A Systematic Review Using Modified ARRIVE and CONSORT Guidelines. Stem Cells Int. 2015;378368.

31. Zambelli A, Poggi G, Da Prada GA, Pedrazzoli P, Cuomo A, Miotti D, Perotti C,Preti P,Robustelli della Cuna G. Clinical toxicity of cryopreserved circulating progenitor cells infusion. Anticancer Res. 1998;18(6B):4705-8.

32. Windrum P, Morris TC, Drake MB, Niederweiser D, Ruutu T. Variation in dimethyl sulfoxide use in stem cell transplantation: a survey of EBMT centres. Bone Marrow Transplant. 2005; 36(7):601-3.

33. Woods EJ, Perry BC, Hockema JJ,Larson L,Zhou D, Goebel WS. Optimized cryopreservation method for human dental pulpderived stem cells and their tissues of origin for banking and clinical use. Cryobiology.2009;59(2):150-7. PMID:19538953.

34. Kawasaki N, Hamamoto $\mathrm{Y}$, Nakajima T,Irie K, Ozawa H. Periodontal regeneration of transplanted rat molars after cryopreservation. Arch Oral Biol.2004; 49(1):59-69. PMID: 14693198 


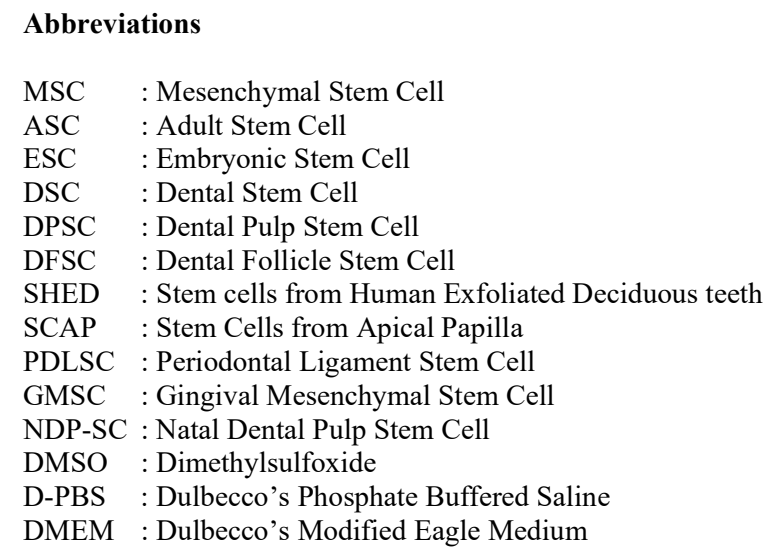

\section{Potential Conflicts of Interests}

None

\section{Acknowledgments}

The authors would like to thank all staff and faculty of College of Dentistry, Research Chair (CDRC) and Stem cell unit of King Saud University and King Khalid University Hospital for their support and guidance in conducting the study.

\section{Corresponding Author}

Manju Philip, Department of Maxillofacial Surgery, College of Dentistry, King Saud University, Riyadh, PO Box 11545, KSA. E-Mail. drmanjuphilip@gmail.com, mphilip@ksu.edu.sa 